\title{
The Role of Perceptual Information in Familiarity-Based Scene Recognition
}

\author{
Alfonso Pitarque and Belén Sáez \\ Universidad de Valencia (Spain)
}

\begin{abstract}
A method to analyze the role of familiarity in recognizing pictures of everyday scenes is introduced. The idea is to manipulate two within-subjects conditions: an experimental condition where the scenes repeat perceptual information (e.g. buildings and/or vehicles) and a control condition. The results show the two conditions did not differ in terms of hit rates, but in the experimental condition there were significantly fewer false alarms, yielding better results, which supports the findings of past research studies that have used verbal materials. This perceptual facilitation was maintained throughout a week-long retention interval. Finally, a detailed analysis of this facilitation shows it was due to a significant reduction in false alarms on know judgments, emphasizing familiarity's role in explaining this effect.
\end{abstract}

Keywords: familiarity, scene recognition, remember and know judgments.

Presentamos un método para analizar el papel que la familiaridad juega en el reconocimiento de fotografías de escenas cotidianas. La idea consiste en manipular dos condiciones intrasujeto: una condición experimental en la que se presentan fotografías en las que se repite información perceptual (p.e. edificios y/o vehículos) frente a otra condición control. Los resultados muestran que no hay diferencias en las tasas de aciertos de ambas condiciones, pero sí una reducción significativa de las falsas alarmas en la condición experimental, lo que provoca una mejor rendimiento en esta condición, patrón de resultados que coincide con el hallado utilizando materiales verbales. Dicha facilitación perceptual se mantiene así mismo tras una semana del estudio de los materiales. Por último el análisis pormenorizado de dicha facilitación nos muestra que es debida principalmente a una reducción significativa de las falsas alarmas en los juicios saber, lo que remarca el papel que la familiaridad juega en la explicación de dicho efecto. Palabras clave: familiaridad, reconocimiento de fotografías, juicios de recordar y saber.

This research was supported by grant PSI2010-17425 from the Spanish Ministerio de Ciencia e Innovación.

Correspondence concerning this article should be addressed to Alfonso Pitarque. Departamento de Metodología, Facultad de Psicología. Avda. Blasco Ibanez 21. 46010 Valencia (Spain). E-mail: pitarque@uv.es 
Recognizing a past experience may be based either on the conscious retrieval of an episodic trace (or recollection) or on an automatic sense of familiarity (or "déjà vu") without recollecting specific details (familiarity; see e.g. Jacoby, 1991; Yonelinas, 2002, for a review). There is increasingly neurological evidence to support the idea that recollection and familiarity are two independent processes with differing neurological bases: the hippocampus and left prefrontal cortex seem to be involved in retrieving episodic traces, while the neighboring perirhinal cortex and parahippocampal structures are associated with familiarity (see Aggleton \& Brown, 2006; Anderson et al., 2008; Diana, Yonelinas, \& Ranganath, 2007; Westerberg, Paller, Holdstock, Mayes, \& Reber, 2006). Experimental data have suggested that with aging and over the course of neurodegenerative disease, the ability to recollect declines, while their effects on familiarity are much less apparent (see e.g. Algarabel et al., 2009; Algarabel, Pitarque, Tomás, \& Mazón, 2010; Algarabel, Rodríguez et al., 2010; Anderson et al., 2008; Westerberg et al., 2006; Wolk, Signoff, \& DeKosky, 2008; Yonelinas, 2002).

Several experimental procedures have been utilized to estimate familiarity and recollection (e.g. the dissociation process paradigm, Jacoby, 1991; the remember/know, or R/K, paradigm, Tulving, 1985; ROC analysis, Donaldson, 1996; associative pair recognition, Yonelinas, 1997, etc.). We generally assume that those procedures succeed in precisely estimating recollection, but estimating familiarity is much more difficult.

To precisely measure familiarity-based recognition in our laboratory, a modified version of the procedure by Parkin et al. (2001) has been utilized, that was previously justified and successfully employed in other studies (see Algarabel \& Pitarque, 2010; Algarabel et al., 2009; Algarabel, Pitarque et al., 2010; Algarabel, Rodríguez et al., 2010; also see Keane, Orlando, \& Verfaellie, 2006). The concept is to distribute participants into two (withinsubjects) recognition conditions: a) an experimental condition where they study and recognize words made up of a 13-letter subset of the alphabet (list A), while the new words introduced during the recognition (distracters) are comprised of the alphabet's remaining 13 letters (list B). This is known as the "non-overlapping condition" (from here on, simply $N O$ ) because words on lists $\mathrm{A}$ and $\mathrm{B}$ do not share a single letter; b) a control condition where participants study and recognize words made up of of the full alphabet (list C). This condition is referred to as the "overlapping condition" (from here on, $O$ ).

If we ensure that participants are unaware of the underlying rule behind selection of words into lists $\mathrm{A}$ and $\mathrm{B}$ in the $N O$ condition (if not, they should be eliminated from the statistical analysis), then differential performance on the $N O$ and $O$ conditions will be due solely to perceptual familiarity-based recognition of those words, because the two conditions differ only in the repetition of some letters, or lack thereof. After the NO recognition task, there is one forced choice task between list A (the studied list) - list B (the non-studied list) word pairs, where half the words on list A had actually been studied and the other half had not (though participants were led to believe they were). This would allow us to measure perceptual familiarity by comparing choice rates on the last task with the number .5 (or probability of a chance hit on the task). The typical pattern of results using this paradigm (see Algarabel \& Pitarque, 2010; Algarabel et al., 2009; Algarabel, Pitarque et al., 2010; Algarabel, Rodríguez et al., 2010; Keane et al., 2006; Parkin et al., 2001) shows similar hit rates across $N O$ and $O$ conditions on the recognition tasks, while there is a significantly lower false alarm rate in the $N O$ condition than in the $O$ condition. Meanwhile, on the forced choice task, words from the studied list (A) were more often chosen than words from the unstudied list (B), whether they had actually studied them before or not. These results can be interpreted in the sense that perceptual manipulation (of which subjects were unaware) affects familiarity judgments (but not recollection judgments).

Most recognition studies conducted in human subjects have measured memory using verbal stimuli. That is problematic because familiarity patterns reported in populations with neurodegenerative disease and in healthy older adults seem to be influenced, or "contaminated," by their verbal capacity and/or level of education. Data collected in our laboratory has reflected this trend (see e.g. Algarabel et al., 2009; Algarabel, Rodríguez et al., 2010; Koontz \& Baskys, 2009; Long, Prat, Jones, Morris, \& Jonatan, 2008). That being said, recent studies have suggested familiarity is not affected by age or cognitive impairment when the materials consist of images (see e.g. Ally, Gold, \& Budson, 2009; Ballesteros, Reales, \& Mayas, 2007; Gutchess \& Park, 2009; O’Connor \& Ally, 2010). Likewise, we know people remember images better than words ("the picture superiority effect," see e.g. Dewhurst \& Conway, 1994; Nelson, Reed, \& Walling, 1976; Paivio, 1971, 1986) and picture memory does not seem to differ in healthy young people and adults (see e.g. Gutchess \& Park, 2009; Park, Puglisi, \& Smith, 1986; Park, Smith, Morrell, Puglisi, \& Dudley, 1990; Smith, Park, Cherry, \& Berkovsky, 1990; Smith, Park, Earles, Shaw, \& Whiting, 1998). Therefore, it seems that a procedure based on recognition of pictures of everyday scenes could be a suitable procedure to overcome the limitations inherent in using verbal materials (see e.g. Manier, Apetroaia, Pappas, \& Hirst, 2004).

Therefore, the present study's first objective will be to apply the procedure described by Parkin et al. (2001) to recognition of real-life scenes that meet criteria like those of word lists A, B, and C. Scenes in list A will include images of buildings and/or vehicles and/or people in an urban environment, while list B will include nature scenes (no buildings, vehicles, or people) and/or animals and/or 
flowers in natural settings; in other words, scenes from lists $\mathrm{A}$ and $\mathrm{B}$ (used in the $N O$ condition) will share no perceptual features. Images in list $\mathrm{C}$ (used in the $O$ condition), however, will share at least one feature with both lists $\mathrm{A}$ and $\mathrm{B}$ (e.g. buildings with animals, buildings in natural settings, vehicles in natural settings, people in natural settings, people with animals, etc.).

In the literature review, we found studies that relate to this objective only indirectly. Langley, Cleary, Kostic, and Woods (2008), for example, analyzed the role of perceptual information in familiarity-based scene recognition with the objective of demonstrating that the "recognition without identification" effect (see Cleary \& Green, 2000; Peynircioglu, 1990) is based solely on familiarity, as in "tip of the tongue" and "déjà vu" type experiences. Cleary and Specker (2007) arrived at similar conclusions using the same experimental paradigm and pictures of faces as materials; Cleary and Reyes (2009) did so using nature pictures. Rajaram (1996), on the other hand, used drawings from Snodgrass and Vanderwart's database (1980) and the $\mathrm{R} / \mathrm{K}$ paradigm, finding that $\mathrm{R}$ judgments were affected by perceptual manipulations like altering font size (Rajaram, 1996, experiment 2) or spelling features (Rajaram, 1998). She did not, however, analyze if perceptual manipulations affect $\mathrm{K}$ judgments, because $\mathrm{R}$ and $\mathrm{K}$ judgments were not independent in this case. Meanwhile, Dobbins, Kroll, and Liu (1998) applied ROC analysis to data collected using the $\mathrm{R} / \mathrm{K}$ paradigm on scene recognition tasks to demonstrate that although $\mathrm{K}$ judgments fit with the predictions of signal detection models, $\mathrm{R}$ judgments are governed by contextual demands that affect the information's distinctiveness, in support of dual-process recognition models. Nevertheless, no study has analyzed the effect of repeating perceptual characteristics on familiarity-based scene recognition.

This study's second objective has to do with the role of repeating perceptual information in false recognition and how that changes over time. In that vein, Diana, Peterson, and Reder (2004) demonstrated that repeating certain perceptual characteristics of words (specifically their font) increased the rate of false alarms. McCabe, Roediger III, McDaniel, and Balota (2009), on the other hand, utilized the $\mathrm{R} / \mathrm{K}$ paradigm to distinguish between recollection-based false recognition and familiarity-based false recognition, showing that age increased the former, but not the latter (see also e.g. Jacoby, Bishara, Hessels, \& Toth, 2005). Given that the usual pattern of results collected using Parkin et al.'s paradigm (2001) is to report significant differences between false alarm rates in $N O$ and $O$ conditions, it would be interesting to analyze whether that is due to recollection judgments (which would pose serious problems for dualprocess recognition models according to which an item that has not been studied cannot be recollected; see e.g. Wixted \& Strech, 2004) or familiarity judgments (due to repeated automatic activation from the repeated perceptual features).
To do so, we will modify Parkin et al.'s paradigm (2001) such that on recognition tasks, subjects will not only make a binary "yes/no" judgment, but a judgment from among three alternatives: "no/yes by recollection $(\mathrm{R}) /$ yes by familiarity (K)" (see e.g. Diana et al., 2004; McCabe et al., 2009). This will allow us to analyze in detail how perceptual repetition affects both correct and false recognitions in $\mathrm{R}$ and $\mathrm{K}$ judgments, and how all change with the passage of time. We will also manipulate temporal conditions between subjects (immediate recognition vs. one week's delay; see e.g. Algarabel, Pitarque, \& Gotor, 2006; Diana et al., 2004; Dudukovic \& Knowlton, 2006; Manier et al., 2004). With the same objective in mind, in the forced choice task, we will follow the procedure proposed by Voss and Paller (2009). That is, we will sequentially present two pictures and after selecting one, subjects will be asked whether their choice was based on recollection $(\mathrm{R})$ or familiarity $(\mathrm{K})$.

\section{Method}

\section{Participants}

Thirty five students from the Psychology Department at the University of Valencia participated in this study, with an average age of 22.81 years $(S D=8.09$ years; age range 20 to 54 years-old; 3 were men, the rest women). They were randomly assigned to one of two conditions: either immediate recognition or recognition after a retention interval of one week. Three subjects were eliminated because they were partially aware of the underlying rule behind scene selection in the $N O$ condition. Ultimately, each condition included 16 participants.

\section{Materials}

From a database of nature scene pictures in color (compiled by the authors), three lists were formed (A, B, C) of 64 pictures each. All were in color with a 1,024 (wide) x 768 (tall) pixel format. The pictures in list A included images of buildings, and/or vehicles, and/or people in an urban environment, while pictures in list B included images of nature scenes (no buildings, cars, or people), and/or animals, and/or flowers in natural settings. Therefore, pictures from lists $\mathrm{A}$ and $\mathrm{B}$ (utilized in the $N O$ condition) shared no perceptual characteristics. Pictures from list $\mathrm{C}$, on the other hand (utilized in the $O$ condition), shared at least one characteristic with list A and one with list B (e.g. buildings with animals, buildings in natural settings, vehicles in natural settings, people in natural settings, people with animals, etc.). The criterion for selecting the 64 pictures in each list was to ask two judges to independently assess (on a scale from 1 to 3 points) how well each picture fit its particular list's criteria (e.g. for list A, "images of buildings, and/or vehicles, and/or people in an urban environment," 
etc.). A picture became part of the list if both judges agreed in assigning it the highest score, such that between-judges reliability for all three lists equaled 1 . Subsequently, 10 students from outside the research team were asked to assess, on a scale from 1 to 5 points, the pleasantness of the 64 pictures in each list. This yielded no significant differences in average evaluations of the three lists $(F(2$, $18)<1, n s)$.

\section{Design}

Two independent variables were manipulated in the recognition tasks: 2 overlap conditions ( $N O$ vs. $O$; withinsubjects) x 2 moments in time (immediate testing vs. testing after one week's delay; between-subjects). The dependent variables included hit rates $(\mathrm{H})$, false alarm rates $(\mathrm{FA})$, and the discrimination indices ( $d$ '; see Table 1). Table 2 displays the hit rates broken down into $\mathrm{R}$ judgment hits (HR) and $\mathrm{K}$ judgment hits (HK). Similarly, FA rates are broken down into $\mathrm{R}$ judgment FAs (FAR) and $\mathrm{K}$ judgment FAs (FAK).

On the forced choice task (CHOICE), two moments in time were manipulated between subjects (immediate vs. delayed test). The dependent variables were, first, hit rate on images the participants actually studied (old) and, second, the rate of choosing stimuli that were not actually studied, but that belonged to the studied list (new-studied). In Table 2 , those rates are broken down into $\mathrm{R}$ and $\mathrm{K}$ judgments.

\section{Procedure}

In the immediate test condition (IMM), each participant carried out two study and recognition tasks with two lists of pictures (presentation order was counterbalanced across subjects):

First, a set of 44 pictures randomly selected from list C were studied (40 target stimuli, plus two filler pictures at the beginning and end of each sequence that were not tested later). They were presented in random order for 1,000 milliseconds each at the center of a computer monitor against a white background, separated by a 500 millisecond interval (white background). Next, subjects performed a distractor task for 5 minutes (simple arithmetic), then were presented with a new recognition task using 40 pictures (20 studied before and 20 new, also from list C). With each picture presented, participants decided whether they recognized it as having been presented before because they remembered details about it (by pushing the R key), it was familiar despite not remembering details about it (by pushing F), or if they thought it had not been presented before (by pushing N). This was done in accordance with the procedure described in Diana et al. (2004) and McCabe et al. (2009). Prior to performing this recognition task, the differences between "remembering" and "knowing" were explained to subjects using Rajaram's instructions (1993), which in short, draw the distinction, respectively, between recognition based on retrieving episodic traces from the item, or on a mere sense of familiarity lacking any specific, episodic information. Each picture remained on the screen until the subject responded. These recognition trials comprised the overlapping condition $(O)$.

Second, each subject studied another set of 44 pictures randomly selected from either list A or list B (40 target stimuli, plus two filler stimuli at the beginning and end of each sequence), presented for 1,000 milliseconds. Next, subjects performed another distractor task for 5 minutes, followed by another recognition task with 40 pictures (20 recently studied and 20 new ones from the complementary list; so if they had studied pictures from list A, the new ones were from $\mathrm{B}$ and vice versa). They responded the same way as in the above recognition task. These recognition trials comprised the non-overlapping condition (NO).

Always after the $N O$ recognition task, subjects completed a forced choice task made up of 40 picture pairs (one was always from list A and one from list B). They were presented sequentially for 2,000 milliseconds each (and labeled at the bottom as "picture A" and "picture B," respectively), separated by a 500 millisecond interval (white background), as per the procedure described by Voss and Paller (2009). The task was to decide which of the two pictures they thought they had seen previously in the study task, photo A or B (by typing either A or B), then to decide whether that choice was based on details they remembered about it, or on familiarity (by typing either R or F). In both decisions, subjects had unlimited time to respond. The instructions emphasized that they had always studied one of the pictures in each pair, which was only true half of the time (old). The other half of the time, participants had not actually seen the picture before, but it belonged to the studied list (new-studied). For each subject, we randomized both the pairs' presentation order and whether the picture from list A or B appeared first or second within the pair.

Finally, a short questionnaire was administered to each participant to ascertain what strategies they had utilized to respond to the previous recognition and forced choice tasks, so as to exclude any participants who had become aware of the relationship between the pictures in lists A and B (NO condition). Anyone who reported responding based on some repeated features or on the dichotomy between a natural vs. urban environment were eliminated (3 were eliminated for this reason; this proportion is on a par with those reported in previous research using lexical materials). Furthermore, we applied statistical control over the data in order to detect any subjects aware of the relationship between the pictures in lists A and B: the idea was that if a subject realized the relationship at the time, either their hit rate in the $N O$ recognition condition would be close to 1 , or in the forced choice task, the rate at which they selected unstudied pictures belonging to the studied list (new-studied) would also be close to 1 . It was decided that 
we would eliminate participants if one of those two rates was greater than or equal to .95 , but no subject ended up being eliminated due to those criteria.

In the test condition with a one-week delay $(D E L)$, participants viewed the two lists employed in the previous study (list C and either A or B, counterbalanced and separated by 5 minutes' rest) and were asked to return a week later to complete the two recognition tasks (also duly counterbalanced), the forced choice task, and to fill out the questionnaire. In addition, they were asked not to consciously try to remember the pictures during their week away, and not to speak amongst themselves about the study's objectives.

It took participants about 30 minutes to complete the above tasks.

\section{Results}

First, to ensure the materials and procedures employed were appropriate, we ensured that neither the list presented (A or B) nor presentation order of the conditions (first $N O$, then $O$, or vice versa) would affect the dependent variables analyzed (hits and false alarms in the $N O$ and $O$ conditions on the two recognition tasks, and hits on the forced choice task). A MANOVA was carried out to assess the effects of 2 lists $\mathrm{x} 2$ presentation orders on these dependent variables, revealing that neither the main effects nor their interaction were significant. These results verify the adequacy of the materials and procedures employed.

Next, we analyzed hit rates on the recognition tasks (see Table 1) by means of a mixed ANOVA with 2 overlapping conditions ( $N O$ vs. $O$; within) x 2 moments in time (IMM vs. DEL tests; between). That analysis determined that neither the overlapping conditions' main effect nor their interaction was significant, but the main effect of moment in time was marginally significant $F(1$, $30)=3.92, p<.06, \eta_{p}^{2}=.12$, in that the hit rate after one week (.68) was lower than in the immediate test (.76).

A similar ANOVA analyzing FAs (see Table 1) revealed the main effects of both overlapping conditions to be significant $F(1,30)=98.65, p<.001, \eta_{\mathrm{p}}^{2}=.77$, along with moment in time $F(1,30)=26.78, p<.001, \eta_{\mathrm{p}}^{2}=.47$, while the interaction between those two variables was not significant. This indicates there were more FAs in the $O$ condition (.30) than the $N O$ condition (.08), and more on the DEL test (.26) than the IMM test (.13).

To calculate individual d' values for each subject, we substituted (if there were any) hit rates of 1 for .98 and false alarm rates of 0 for .02 (see Macmillan \& Creelman, 1991). The mixed $2 \times 2$ ANOVA on d'values (see Table 1) showed that both the main effects of overlap condition $F(1$, $30)=71.20, p<.001, \eta_{\mathrm{p}}^{2}=.70$ and moment in time $F(1$, $30)=37.46, p<.001, \eta_{p}^{2}=.56$ were significant, while their interaction was not. This indicates that performance in the $N O$ condition (2.25) was better than in the $O$ condition (1.13) and better on the IMM test (2.11) than the DEL test (1.26).

We went on to analyze data from the forced choice task (CHOICE; see Table 1). Regarding the images actually studied (old), they were better recalled on the IMM test than the DEL test $(t(30)=4.36, p<.001)$, and both means differed significantly from .50 , the probability of a chance hit $t(15)=21.19, p<.001, t(15)=12.19, p<.001$, respectively. As for the images not seen before but belonging to the studied list (new-studied), the difference between the IMM and DEL tests was not significant, but both means differed significantly from the value $.50 t(15)$ $=7.71, p<.001 ; t(15)=6.26, p<.001$, respectively. This clearly entails that perceptual familiarity played a role in that task.

These findings replicate the results reported by other laboratories using lexical materials (see e.g. Algarabel \& Pitarque, 2010; Algarabel et al., 2009; Algarabel, Pitarque et al., 2010; Algarabel, Rodríguez et al., 2010; Keane et al., 2006; Parkin et al., 2001) by showing that the perceptual facilitation found in the $N O$ recognition condition, as compared to the $O$ condition, is not due to differences in hit rate, but to a lower rate of false alarms in the $N O$ condition. On the other hand, on the forced choice task, subjects tended to subconsciously choose materials from the studied list, whether they had been studied before or not, because they shared certain perceptual features repeated throughout the study task. Last, the passage of time was found to decrease hits and increase false alarms proportionally in the two overlap conditions.

Table 1

Mean Number (and SEM) of Hits (H), False Alarms (FA) and d'in the Non-overlapping (NO OVER) vs. Overlapping (OVER) Conditions of Immediate and Delayed Recognition (IMM and DEL), as Well as Average Number of Hits on Previously Studied Stimuli (old) and Unstudied Stimuli from the Studied List (new-studied) on the Forced Choice Task (CHOICE)

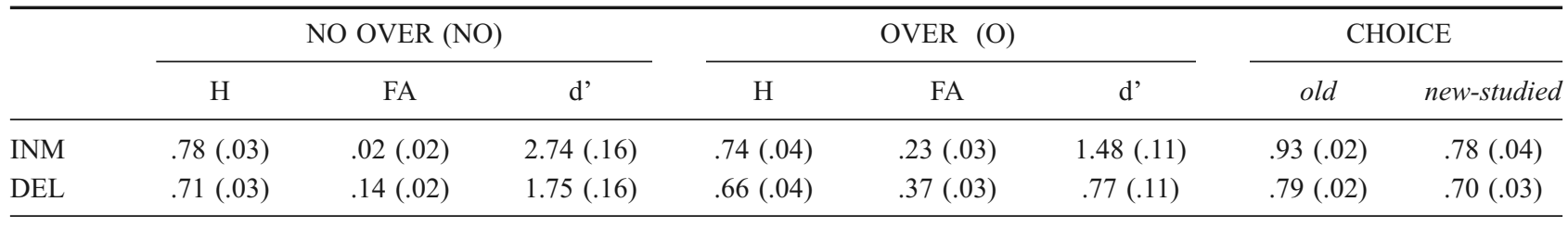


Table 2

Mean Number (and SEM) of Hits (H) and False Alarms (FA) from Table 1 Broken Down into Recollection (R) and Familiarity (K) Judgments

\begin{tabular}{|c|c|c|c|c|c|c|c|c|c|c|c|c|}
\hline & \multicolumn{4}{|c|}{ NO OVER (NO) } & \multicolumn{4}{|c|}{ OVER (O) } & \multicolumn{4}{|c|}{ CHOICE } \\
\hline & H R & H K & FA R & FA K & H R & H K & FA R & FA K & old-R & old-K & new-stud-R & new-stud-K \\
\hline INM & $.56(.04)$ & $.22(.03)$ & $.01(.01)$ & $.02(.02)$ & $.52(.04)$ & $.22(.04)$ & $.04(.01)$ & $.19(.02)$ & $.56(.05)$ & $.37(.04)$ & $.13(.03)$ & $.66(.04)$ \\
\hline DEL & $.31(.04)$ & $.39(.03)$ & $.04(.02)$ & $.11(.02)$ & $.31(.04)$ & $.34(.04)$ & $.08(.02)$ & $.29(.02)$ & $.27(.04)$ & $.52(.04)$ & $.16(.03)$ & $.54(.03)$ \\
\hline
\end{tabular}

With respect to our study's second objective, we will now analyze the role of our manipulations, breaking down hits and false alarms into R and $\mathrm{K}$ judgments (see Table 2).

We began by analyzing hit rates on $\mathrm{R}$ judgments (HR; see Table 2) using a mixed ANOVA with 2 overlapping conditions ( $N O$ vs. $O$; within) $\times 2$ moments in time (IMM vs. DEL tests; between). This revealed the only significant main effect was that of moment in time $F(1,30)=16.97$, $p<.001, \eta_{\mathrm{p}}^{2}=.36$, because $\mathrm{R}$ judgments' hit rate after a week (.31) was lower than on the IMM test (.54). A similar ANOVA applied to hit rates on K judgments (HK; see Table 2), likewise, showed that only the main effect of moment in time $F(1,30)=13.93, p=.001, \eta_{\mathrm{p}}^{2}=.32$ was significant, but in the opposite direction. $\mathrm{K}$ judgments' hit rate after a week (.37) was higher than on the IMM test (.22). In sum, the passage of time lowered $\mathrm{R}$ hits while increasing $\mathrm{K}$ hits in both overlapping conditions. This indicates that due to the loss of episodic traces over time, $\mathrm{R}$ responses became $\mathrm{K}$ responses (see e.g. Algarabel et al., 2006; Knowlton \& Squire, 1995).

With regards to false alarms in R judgments (FAR; see Table 2), the ANOVA showed the main effects of overlapping condition and moment in time were significant, but their interaction was not $F(1,30)=9.22, p=.005, \eta^{2}$ p $=.24 ; F(1,30)=4.95, p<.05, \eta_{\mathrm{p}}^{2}=.14$, respectively, because they made more FAs on $\mathrm{R}$ in the $O$ condition (.06) than the $N O$ condition (.03) and more on the DEL test (.06) than the IMM test (.03). The ANOVA applied to false alarms in K judgments (FAK; see Table 2) showed a similar pattern of results: the main effects of the overlapping conditions and moment in time turned out to be significant, but their interaction did not $F(1,30)=115.40, p<.001$, $\eta_{\mathrm{p}}^{2}=.79 ; F(1,30)=16.40, p<.001, \eta_{\mathrm{p}}^{2}=.35$, respectively. This shows that more FAs on $\mathrm{K}$ were made in the $O$ condition (.24) than the $N O$ condition (.06) and on the DEL test (.20) than the IMM test (.10). These results clearly convey that the explanation for the perceptual facilitation effect found using Parkin et al.'s paradigm (2001), and words as well as images, suggests that the decrease in false alarms in the $N O$ condition is mainly due to a decrease in FAKs.

Next, we analyzed data from the forced choice task (CHOICE; see Table 2). There were more HR on the images actually studied (old) on the IMM test than the DEL test $t(30)=4.42, p<.001$, but there were more HK on the DEL test than the IMM test $t(30)=2.53, p<.05$. This pattern reiterates the results of the two recognition tasks. Concerning images that were not studied previously but belonged to the studied list (new-studied), the difference between the IMM and DEL tests was not significant on R judgments, but it was on $\mathrm{K}$ judgments, favoring the IMM test $t(30)=$ $2.20, p<.05$. This indicates familiarity is also the main source of the perceptual facilitation reflected in this last dependent variable.

Some authors (see e.g. Dudukovic \& Knowlton, 2006; Yonelinas, 2002) argue that utilizing the $R / K$ paradigm, $\mathrm{K}$ responses do not measure an item's true familiarity, but rather the probability that it is familiar when episodic information is not available, such that $K$ responses underestimate familiarity. With that in mind, it has been proposed that true familiarity $(F)$ can be estimated by an equation proposed by Yonelinas and Jacoby (1995), $F=$ $K /(1-R)$. We plugged our data into that equation and yielded virtually the same results as the ones discussed above corresponding to $K$ responses. More specifically, a mixed ANOVA was carried out with 2 overlapping conditions (NO vs. $O$ ) x 2 moments in time (IMM vs. DEL tests) on $\mathrm{F}$ hit rates, showing that neither overlapping conditions nor time, nor their interaction, had a significant effect. An ANOVA applied to $\mathrm{F}$ false alarms yielded the same results as the ANOVA on $K$ judgment false alarms. Both the main effects of overlapping conditions and moment in time were significant $F(1,30)=106.86, p<.001, \eta_{\mathrm{p}}^{2}=.78 ; F(1,30)$ $=18.89, p<.001, \eta_{\mathrm{p}}^{2}=.39$, respectively, but their interaction was not. This confirms that more familiarity FAs were made in the $O$ condition (.26) than the $N O$ condition (.06), and more on the DEL test (.21) than the IMM test (.11). Finally, analyses on F in the forced choice task revealed higher hit rates on the IMM test than the DEL test in the case of images actually studied .86 and .70, respectively; $t(30)=2.99, p=.005$, as well as and those that were not, but belonged to the studied list .75 and .64 , respectively; $t(30)=2.07, p<.05$.

This second block of results conveys that on recognition and forced choice tasks, with the passage of time, $\mathrm{R}$ judgment hits decrease, while $\mathrm{K}$ judgment hits increase. By the same token, time increased false recognitions in the case of both $\mathrm{R}$ and $\mathrm{K}$ judgments. Last, data from the forced 
choice task show that in recognizing an image one actually studied, episodic components as well as familiarity intervene. Yet when recognizing an image not actually studied that belongs to the studied list, mainly familiarity components intervene. This supports our use of this procedure here.

\section{Discussion}

First of all, these results convey a significant perceptual facilitation in the $N O$ condition compared to the $O$ condition, not because there was a higher hit rate in the $N O$ condition (which would suggest facilitation was conscious and invalidate our procedure), but to a lower rate of false alarms. Along those lines, our results support numerous others in asserting that implicit processes have an impact on recognition (which is an explicit or conscious process; see e.g. Cleary \& Green, 2000; Langley et al., 2008; Manier et al, 2004). These results reiterate the findings of studies that have used verbal materials (see e.g. Algarabel \& Pitarque, 2010; Algarabel et al., 2009; Algarabel, Pitarque et al., 2010; Algarabel, Rodríguez et al., 2010; Keane et al., 2006; Parkin et al., 2001) and demonstrate that pictorial materials like the ones presented here would be adequate to elicit that effect in populations with verbal impairment. In addition, because pictures are holistically encoded, familiarity can be used as a compensatory mechanism for retrieval in populations with memory deficits (see e.g. Quamme, Yonelinas, \& Norman, 2007).

On another note, the perceptual facilitation observed was maintained for a week after the materials were studied, which would be hard to explain using single-process models of recognition based solely on enhancing the memory trace. This data is congruent with data from other laboratories (see e.g. Algarabel et al., 2009; Algarabel, Rodríguez et al., 2010; Anderson et al., 2008; Parkin et al., 2001) in showing that familiarity does not decline with age, but recollection does. Evidence for the same pattern of results was found in the forced choice task, considering the rate of actually unstudied images chosen that really belonged to the studied list. We have confirmed here that this task is another valid procedure to estimate this perceptual facilitation. We previously expressed (see e.g. Algarabel, Pitarque et al., 2010), and these data seem to verify, that the facilitation we found here seems to be more the result of an implicit learning (like grammar learning; see e.g. Reber, 1967) of the covariations among perceptual and conceptual features repeated across different pictures.

Next, our analysis of hits on the immediate test demonstrates they were due to both $\mathrm{R}$ and $\mathrm{K}$ responses (though $\mathrm{R}$ was predominant). On the delayed test, meanwhile, probably due to a loss of episodic details over time, a clear conversion from $\mathrm{R}$ responses to $\mathrm{K}$ responses occurred (see e.g. Knowlton \& Squire, 1995). On the other hand, our false alarms analysis reveals that the majority involved $\mathrm{K}$ judgments, which increase over time. This also occurred in the case of $\mathrm{R}$ false alarms, though to a lesser extent. Our global results on $\mathrm{R}$ and $\mathrm{K}$ hit and false alarm rates support recent meta-analysis data (Gardiner, Ramponi, \& Richardson-Klavehn, 2002; McCabe et al., 2009) and data gathered in other laboratories (see e.g. Algarabel et al., 2006; Diana et al., 2004; Dudukovic \& Knowlton, 2006), which endorses the methodology employed here and substantiates the postulates of dual-process models of memory (see e.g. Yonelinas, 2002).

Finally, regarding this study's second objective in particular, that is, to compare FAs in the $N O$ and $O$ conditions, which is essential to understanding the perceptual facilitation repeatedly observed using this paradigm, our data show that in the control, $O$ condition, significantly more FAs were produced than in the $N O$ condition. Furthermore, the majority occurred on $\mathrm{K}$ judgments. The manipulation applied in the $N O$ experimental condition brought about a drastic reduction in said FAs (e.g. Israel \& Schacter, 1997, showed that distinctive perceptual information leads subjects to make fewer false recognitions, as occurred in our $N O$ condition). This demonstrates that familiarity is more sensitive to perceptual manipulations than recollection is, as dual-process models postulate.

By way of summary, the data presented here replicate past findings using verbal materials and enable us to recommend employing pictures of natural scenes to determine perceptual familiarity-based recognition. On another note, comparing data from the immediate and delayed tests demonstrates that this perceptual facilitation is a long-lasting effect, one that cannot be explained merely by automatic activation of repeated perceptual features. It has more to do with an implicit learning of the underlying rules behind the $N O$ condition's materials. Finally, our analysis of the pattern of perceptual facilitation suggests it resulted from a lower number of FAs in the $N O$ condition than in the $O$, control condition. In both conditions, the majority of FAs took place in $\mathrm{K}$ judgments.

Thanks to the data collected here, our next objective will be to apply the procedure and materials employed here in samples of different age groups and/or levels of neurodegenerative disease (e.g. healthy adults, mild cognitive impairment, Alzheimer's disease). This would contribute conclusive data to the controversies over whether familiarity declines with age or not, and as to the progression of neurodegenerative disease (see e.g. O'Connor \& Ally, 2010).

\section{References}

Aggleton, J. P., \& Brown, M. W. (2006). Interleaving brain systems for episodic and recognition memory. Trends in Cognitive Sciences, 10, 455-463. http://dx.doi.org/10.1016/j.tics.2006.08.003 
Algarabel, S., Escudero, J., Mazón, J. F., Pitarque, A., Peset, V., \& Lacruz, L. (2009). Familiarity based recognition in young, healthy aged people, mild cognitive impaired and Alzheimer's disease patients. Neuropsychologia, 47, 2056-2064. http://dx.doi.org/10.1016/j.neuropsychologia.2009.03.016

Algarabel, S., \& Pitarque, A., (2010). Familiarity changes as a function of perceptual shifts. The Spanish Journal of Psychology, $13,518-524$.

Algarabel, S., Pitarque, A., \& Gotor, A. (2006). Effect of retention interval on the simultaneous cognate-noncognate and remember-know mirror effects. Memory, 14, 79-86. http://dx.doi.org/10.1080/09658210444000539

Algarabel, S., Pitarque, A., Tomás, J. M., \& Mazón, J. F. (2010). Explorations on familiarity produced by words with specific combinations of letters. The European Journal of Cognitive Psychology, 22, 265-285. http://dx.doi.org/10.1080/095414409 02767818

Algarabel, S., Rodríguez, L. A., Escudero, J., Fuentes, M., Peset, V., Pitarque, A., ... Mazón, J. F. (2010). Recognition by familiarity is preserved in Parkinson's witout dementia and Lewy-Body disease. Neuropsychology, 24, 599-607. http://dx.doi.org/10.1037/a0019221

Ally, B. A., Gold, C. A., \& Budson, A. E. (2009). An evaluation of recollection and familiarity in Alzheimer's desease and mild cognitive impairment using receiver operating characteristics. Brain \& Cognition, 69, 504-513. http://dx.doi.org/10.1016/ j.bandc.2008.11.003

Anderson, N. D., Ebert, P. L., Jennings, J. M., Grady, C. L., Cabeza, R., \& Graham. S. J. (2008). Recollection- and familiarity-based memory in healthy aging and amnesic mild cognitive impairment. Neuropsychology, 22, 177-187. http://dx.doi.org/10.1037/0894-4105.22.2.177

Ballesteros, S., Reales, J. M., \& Mayas, J. (2007). Picture priming in normal aging and Alzheimer's disease. Psicothema, 19, 239-244.

Cleary, A. M., \& Greene, R. L. (2000). Recognition without identification. Journal of Experimental Psychology: Learning, Memory, and Cognition, 26, 1063-1069. http://dx.doi.org/ 10.1037//0278-7393.26.4.1063

Cleary, A. M., \& Reyes, N. L. (2009). Scene recognition without identification. Acta Psychologica, 131, 53-62. http://dx.doi.org/ 10.1016/j.actpsy.2009.02.006

Cleary, A. M., \& Specker, L. E. (2007). Recognition without face identification. Memory and Cognition, 35, 1610-1619. http://dx.doi.org/10.3758/BF03193495

Dewhurst, S. A., \& Conway, M. A. (1994). Pictures, images, and recollective experience. Journal of Experimental Psychology: Learning, Memory, and Cognition, 20, 1088-1098. http://dx.doi.org/10.1037//0278-7393.20.5.1088

Diana, R. A., Peterson, M. J., \& Reder, L. M. (2004). The role of spurious feature familiarity in recognition memory. Psychonomic Bulletin \& Review, 11, 150-156. http://dx.doi.org/ 10.3758/BF03206475

Diana, R. A., Yonelinas, A. P., \& Ranganath, C. (2007). Imaging recollection and familiarity in the medial temporal lobe: A three-component model. Trends in Cognitive Sciences, 11, 379-386. http://dx.doi.org/10.1016/j.tics.2007.08.001

Dobbins, I. G., Kroll, N. E. A., \& Liu, Q. (1998). Confidenceaccuracy inversions in scene recognition: A remember-know analysis. Journal of Experimental Psychology: Learning, Memory, and Cognition, 24, 1306-1315. http://dx.doi.org/ 10.1037//0278-7393.24.5.1306

Donaldson, W. (1996). The role of decision processes in remembering and knowing. Memory \& Cognition, 24, 523533. http://dx.doi.org/10.3758/BF03200940

Dudukovic, N. M., \& Knowlton, B. J. (2006). Remember-know judgements and retrieval of contextual details. Acta Psychologica, 122, 160-173. http://dx.doi.org/10.1016/j.actpsy. 2005.11.002

Gardiner, J. M., Ramponi, C., \& Richardson-Klavehn, A. (2002). Recognition memory and decision processes: A meta-analysis of remember, know, and guess responses. Memory, 10, 8398. http://dx.doi.org/10.1080/09658210143000281

Gutchess, A. H., \& Park, D. C. (2009). Effects of ageing on associative memory for related and unrelated pictures. European Journal of Cognitive Psychology, 21, 235-254. http://dx.doi.org/10.1080/09541440802257274

Israel, L., \& Schacter, D. L. (1997). Pictorial encoding reduces false recognition of semantic associates. Psychological Bulletin \& Review, 4, 577-581. http://dx.doi.org/10.3758/BF03214352

Jacoby, L. L. (1991). A process dissociation framework: Separating automatic from intentional uses of memory. Journal of Memory \& Language, 30, 513-541. http://dx.doi.org/10.1016/0749596X(91)90025-F

Jacoby, L. L., Bishara, A. J., Hessels, S., \& Toth, J. P. (2005). Aging, subjective experience, and cognitive control: Dramatic false remembering by older adults. Journal of Experimental Psychology: General, 134, 131-148. http://dx.doi.org/10.1037/ 0096-3445.134.2.131

Keane, M. M., Orlando, F., \& Verfaellie, M. (2006). Increasing the salience of fluency cues reduces the recognition memory impairment in amnesia. Neuropsychologia, 44, 834-839. http://dx.doi.org/10.1016/j.neuropsychologia.2005.08.003

Knowlton, B. J., \& Squire L. R. (1995). Remembering and knowing: Two different expressions of declarative memory. Journal of Experimental Psychology: Learning, Memory, and Cognition, 21, 699-710. http://dx.doi.org/10.1037//02787393.21.3.699

Koontz, J., \& Baskys, A. (2009). The cognitive reserve hypothesis: Truth or fiction? Directions in Psychiatry, 29, 15-21.

Langley, M. M., Cleary, A. M., Kostic, B. N., \& Woods, J. A. (2008). Picture recognition without picture identification: A method for assessing the role of perceptual information in familiarity-based picture recognition. Acta Psychologica, 127, 103-113. http://dx.doi.org/10.1016/j.actpsy.2007.03.001

Long, D., Prat, C., Jones, C., Morris, P., \& Jonatan, E. (2008). The importance of knowledge in vivid text memory: An individual-differences investigation of recollection and familiarity. Psychonomic Bulletin \& Review, 15, 604-609. http://dx.doi.org/10.3758/PBR.15.3.604 
McCabe, D. P., Roediger III, H. L., McDaniel, M. A., \& Balota, D. A. (2009). Aging reduces veridical remembering but increases false remembering: Neuropsychological test correlates of remember-know judgments. Neuropsychologia, 47, 2164 2173. http://dx.doi.org/10.1016/j.neuropsychologia.2008.11.025

Macmillan, N. A., \& Creelman, C. D. (1991). Detection theory: A user's guide. Cambridge, MA: Cambridge University Press.

Manier, D., Apetroaia, I., Pappas, Z., \& Hirst, W. (2004). Implicit contributions of context recognition. Consciousness \& Cognition, 13, 471-483. http://dx.doi.org/10.1016/j.concog.2004.06.006

Nelson, D. L., Reed, U. S., \& Walling, J. R. (1976). Pictorial superiority effect. Journal of Experimental Psychology: Human Learning \& Memory, 2, 523-528. http://dx.doi.org/10.1037//02787393.2.5.523

O'Connor, M. K., \& Ally, B. A. (2010). Using stimulus form change to understand memorial familiarity for pictures and words in patients with mild cognitive impairment and Alzheimer's disease. Neuropsychologia, 48, 2068-2074. http://dx.doi.org/10.1016/j.neuropsychologia.2010.03.027

Park, D. C., Puglisi, J. T., \& Smith, A. D. (1986). Memory for pictures: Does an age-related decline exist?. Psychology and Aging, 1, 11-17. http://dx.doi.org/10.1037//0882-7974.1.1.11

Park, D. C., Smith, A. D., Morrell, R. W., Puglisi, J. T., \& Dudley, W. N. (1990). Effects of contextual integration on recall of pictures by older adults. Journal of Gerontology: Psychological Sciences, 45, 52-57.

Parkin, A., Ward, J., Squires, E., Furbear, H., Clark, A., \& Townshend, J. (2001). Data-driven recognition memory: A new technique and some data on age differences. Psychonomic Bulletin and Review, 8, 812-819. http://dx.doi.org/10.3758/BF03196222

Paivio, A. (1971). Imagery and verbal processes. New York, NY: Holt, Rinehart, \& Winston.

Paivio, A. (1986). Mental representations: A dual-coding approach. New York, NY: Oxford University Press

Peynircioglu, Z. F. (1990). A feeling-of-recognition without identification. Journal of Memory and Language, 29, 493500. http://dx.doi.org/10.1016/0749-596X(90)90068-B

Quamme, J. R., Yonelinas, A. P., \& Norman, K. A. (2007). Effect of unitization on associative recognition in amnesia. Hippocampus, 17, 192-200. http://dx.doi.org/10.1002/hipo.20257

Rajaram, S. (1993). Remembering and knowing. Two means of access to the personal past. Memory \& Cognition, 21, 89102. http://dx.doi.org/10.3758/BF03211168

Rajaram, S. (1996). Perceptual effects on remembering: Recollective processes in picture recognition memory. Journal of Experimental Psychology: Learning, Memory, and Cognition, 22, 365-377. http://dx.doi.org/10.1037//0278-7393.22.2.365

Rajaram, S. (1998). The effects of conceptual salience and perceptual distinctiveness on conscious recollection. Psychonomic Bulletin and Review, 5, 71-78. http://dx.doi.org/ 10.3758/BF03209458
Reber, A. S. (1967). Implicit learning of artificial grammars. Journal of Verbal Learning and Verbal Behavior, 6, 855-863. http://dx.doi.org/10.1016/S0022-5371(67)80149-X

Smith, A. D., Park, D. C., Cherry, K., \& Berkovsky, K (1990). Age differences in memory for concrete and abstract pictures. Journal of Gerontology: Psychological Sciences, 45, 205-209.

Smith, A. D., Park, D. C., Earles, J. L. K., Shaw, R. J., \& Whiting, W. L. (1998). Age differences in context integration in memory. Psychology and Aging, 13, 21-28. http://dx.doi.org/10.1037//08827974.13.1.21

Snodgrass, J. L., \& Vanderwart, M. (1980). A standardized set of 260 pictures: Norms for name agreement, image agreement, familiarity and visual complexity. Journal of Experimental Psychology: Human Learning and Memory, 6, 174-215. http://dx.doi.org/10.1037/0278-7393.6.2.174

Tulving, E. (1985). Memory and consciousness. Canadian Psychology, 26, 1-12. http://dx.doi.org/10.1037/h0080017

Voss, J. L., \& Paller, K. A. (2009). An electrophysiological signature of unconscious recognition memory. Nature Neuroscience, 12, 349-355. http://dx.doi.org/10.1038/nn.2260

Westerberg, C. E., Paller, K. E., Holdstock, J. S., Mayes, A. R., \& Reber, P. J. (2006). When memory does not fail: Familiaritybased recognition in mild cognitive impairment and Alzheimer's disease. Neuropsychology, 20, 193-205. http://dx.doi.org/10.1037/0894-4105.20.2.193

Wixted, J. T., \& Stretch, V. (2004). In defense of the signaldetection interpretation of remember/know judgments. Psychonomic Bulletin \& Review, 11, 616-641. http://dx.doi.org/ 10.3758/BF03196616

Wolk, D. A., Signoff, E. D., \& DeKosky, S. T. (2008). Recollection and familiarity in amnestic mild cognitive impairment: A global decline in recognition memory. Neuropsychologia, 46, 1965-1978. http://dx.doi.org/10.1016/j.neuropsychologia.2008. 01.017

Yonelinas, A. P. (1997). Recognition memory ROCs for item and associative information: The contribution of recollection and familiarity. Memory \& Cognition, 25, 747-763. http://dx.doi.org/ 10.3758/BF03211318

Yonelinas, A. P. (2002). The nature of recollection and familiarity: A review of 30 years of research. Journal of Memory and Language, 46, 441-517. http://dx.doi.org/10.1006/jmla.2002. 2864

Yonelinas, A. P., \& Jacoby, L. L. (1995). The relation between remembering and knowing as bases for recognition: Effects of size congruency. Journal of Memory \& Language, 34, 622643. http://dx.doi.org/10.1006/jmla.1995.1028

Received May 23, 2011 Revision received October 18, 2011 Accepted November 2, 2011 